\title{
Katharina Schembs
}

\section{Korporativismus, Arbeit und Propaganda im faschistischen Italien}

(1922-1945)

„Im zähen Willen des italienischen Volkes zu arbeiten und zu sparen liegt die sichere Garantie seiner Zukunft.“ - Mit diesem Zitat Mussolinis ist eine Propagandapostkarte von 1938 unterschrieben (Abb. 1). Sie zeigt einen überaus muskulösen oberkörperfreien Arbeiter, der mit einem Hammer ein glühendes Stück Eisen auf einem Amboss bearbeitet. Im Zusammenspiel mit der Bildunterschrift wird die Zukunft der Nation also an die Arbeitsamkeit der Italiener geknüpft. Stilisiert zum vorbildlichen uomo nuovo fascista, begannen Arbeiterfiguren wie diese ab 1922 die faschistische Bildpropaganda zu bevölkern.

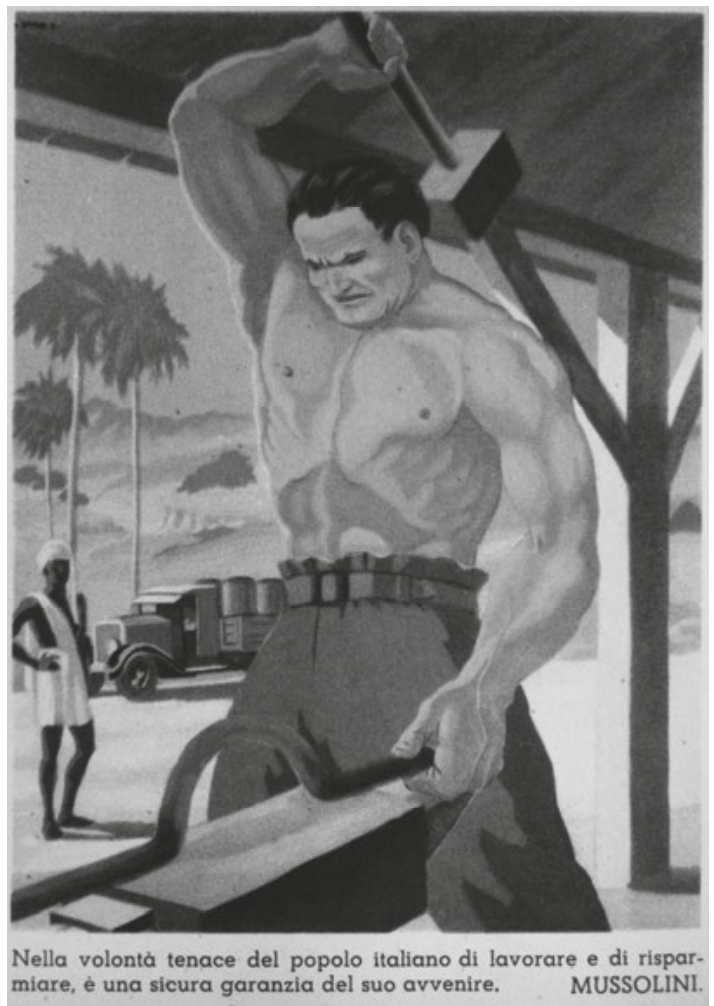

Abb. 1: „Nella volontà tenace del popolo italiano di lavorare...", Cassa di Risparmio delle Provincie Lombarde, Postkarte $105 \times 148$ mm, Mailand 1938 . (c) Wolfsoniana - Fondazione regionale per la Cultura e lo Spettacolo, Genua. 
Denn nicht nur im nationalsozialistischen Deutschland, auch im faschistischen Italien stellte Arbeit ein zentrales Diskursfeld bei der öffentlichen Propaganda des Regimes dar. Ab 1922 sollte als Reaktion auf Arbeiterunruhen und als Lösung der sozialen Frage mit dem Korporativismus ein sozioökonomisches Gegenmodell $\mathrm{zu}$ Kapitalismus und Kollektivismus institutionalisiert werden. ${ }^{1}$ Durch die vertikale Gliederung nach Berufsständen in staatlich kontrollierte Körperschaften, die dem Korporationsministerium als zentralem wirtschaftspolitischen Steuerungselement unterstanden, wurde die Befriedung überkommener Klassenkonflikte angestrebt. ${ }^{2}$ Zwar schritt die Institutionalisierung nur schleppend voran und Funktionalität wie Effektivität der korporatistischen Organe wurden berechtigterweise bereits zeitgenössisch angezweifelt. ${ }^{3}$ Dennoch kam es in diesem sozioökonomischen Umfeld erstmals dazu, dass Arbeit einen zentralen Stellenwert innerhalb des politischen Programms einer italienischen Nationalregierung einnahm. Als keineswegs ausschließlich wirtschaftliches Reformprogramm avancierte der Korporativismus gar zur staatstragenden Ideologie und spielte eine immense Rolle in der Selbstrepräsentation des Regimes. ${ }^{4}$ Die korporatistischen Reformen koinzidierten mit dem Ausbau und der erstmaligen Nutzung der modernen Massenmedien im großen Stile zu politischen Zwecken. ${ }^{5}$ Das zunächst abstrakte Wirtschaftsmodell wurde nun in der faschistischen Propaganda allgegenwärtig. ${ }^{6}$ In der weitläufig vertriebenen Bildpropaganda, die in Anlehnung an Massentheorien des ausgehenden 19. Jahrhunderts von den Faschisten für am geeignetsten befunden wurde, die als irrational konzipierte Masse zu erziehen, wimmelte es geradezu von Arbeiterfiguren. $^{7}$

Obwohl die Faschisten Bildpropaganda als zentrales massenpolitisches Instrument erachteten, war sie bisher kaum Gegenstand eingehender Studien.

1 Simonetta Falasca-Zamponi, Fascist Spectacle. The Aesthetics of Power in Mussolini's Italy, Berkeley 1997, S. 133.

2 Alexander Nützenadel, Korporativismus und Landwirtschaft im faschistischen Italien, in: Aldo Mazzacane (Hrsg.), Korporativismus in den südeuropäischen Diktaturen, Frankfurt a.M. 2005, S. 346; Arnd Bauerkämper, Der Faschismus in Europa 1918-1945, Stuttgart 2006, S. 61.

3 Alexander Nützenadel, Landwirtschaft, Staat und Autarkie. Agrarpolitik im faschistischen Italien (1922-1943), Tübingen 1997, S. 339; Nützenadel, Korporativismus, S. 346; Gianpasquale Santomassimo, La terza via fascista: Il mito del corporativismo, Rom 2006.

4 Falasca-Zamponi, Spectacle, S. 132.

5 Clemens Zimmermann, Medien im Nationalsozialismus. Deutschland 1933-1945, Italien 1922-1943, Spanien 1936-1951, Wien 2007, S. 67; Giovanni Sedita, Gli intellettuali di Mussolini. La cultura finanziata dal fascismo, Florenz 2010, S. 180.

6 Zimmermann, Medien, S. 67; Giuseppe Bottai, La Carta del lavoro, Rom 1928.

7 Falasca-Zamponi, Spectacle, S. 20f.: Mussolini stand mit dem Begründer der Massenpsychologie Gustave Le Bon in engem persönlichen Kontakt und betrachtete ihn gar als seinen Mentor. 
Dabei kann deren Analyse neben der Frage nach dem Verhältnis zwischen Propaganda und Realität weitere wichtige Aspekte der Kulturgeschichte des Faschismus erhellen, die potentiell über Erkenntnismöglichkeiten von Schriftquellen hinausgehen. Dabei ist $\mathrm{zu}$ fragen, auf welchem Typus Arbeiter der Fokus der faschistischen Propaganda lag. Ferner sind Einsichten in die Konstruktion von Geschlechterrollen mithilfe von Bildmedien zu erwarten. Welche Folgen hatte die Kopplung der nationalen Identität an Arbeit für NichtItaliener? Und schließlich: Inwiefern wurde die propagandistische Kategorie der Arbeit in Kriegszeiten modifiziert?

Nach der Erläuterung der kulturpolitischen Rahmenbedingungen im faschistischen Italien wird die Bildpropaganda in Form von Plakaten, Postkarten und anderen Printmedien vorranging auf ihre Bildsujets hin befragt. Dabei wird von einem aktivischen Bildbegriff ausgegangen, wie ihn die rezente historische Bildforschung ${ }^{8}$ postuliert und wie er auch dem konstruktivistischen Verständnis der Faschisten von Kunst und Propaganda entsprach: Die künstlerische Bildproduktion sollte die neue korporatistische Ordnung nicht nur abbilden oder illustrieren, sondern, ihr vorgeschaltet, aktiv zu deren Errichtung und Diffusion beitragen. ${ }^{9}$

\section{Kulturpolitik und Propaganda im faschistischen Italien}

Im Hinblick auf die mit der korporatistischen Umgestaltung einhergehende Kulturpolitik im faschistischen Italien sollten ministeriale Neugründungen oder Erweiterungen eine zentralisierte Koordination der staatlichen Propaganda garantieren. ${ }^{10}$ So wurde die 1922 gegründete Presseabteilung (Ufficio Stampa del Capo del Governo) bis 1937 sukzessive zum Ministerium für Populärkultur (Ministero della Cultura Populare) ausgebaut, für dessen Konzeption das deutsche Reichsministerium für Volksaufklärung und Propaganda Pate stand. ${ }^{11} \mathrm{Im}$ Ge-

8 Gerhard Paul, Die aktuelle Historische Bildforschung in Deutschland. Themen - Methoden Probleme - Perspektiven, in: Jens Jäger/Martin Knauer (Hrsg.), Bilder als historische Quellen? Dimension der Debatten um historische Bildforschung. München 2009, S. 125-148.

9 Monica Cioli, Il fascismo e la „sua“ arte: Dottrina e istituzioni tra futurismo e Novecento, Florenz 2011, S. XXI.

10 Nicola Tranfaglia, La stampa del regime, 1932-1943. Le veline del Minculpop per orientare l'informazione, Mailand 2005, S. 18.

11 Gustavo Corni, State and Society: Italy and Germany compared, in: Richard Bosworth (Hrsg.), The Oxford Handbook of Fascism, Oxford 2009, S. 279-295, S. 293. 
gensatz zum deutschen Gegenstück beschränkten sich die Praktiken der Zensurpolitik im faschistischen Italien in der Frühphase jedoch größtenteils auf die Aussprache von Empfehlungen. ${ }^{12}$ Kontrolle und Kooptation wurden unter Mussolini weniger über Einschüchterungsmaßnahmen als vielmehr über materielle Anreize ausgeübt. Da das staatliche Finanzaufkommen im kulturellen Bereich ungekannte Ausmaße erreichte, eröffneten sich vielen Kulturschaffenden neue Möglichkeiten der Finanzierung. ${ }^{13}$ Vom kulturpolitisch liberaleren Klima und vom größtenteils freiwilligen Charakter der Kollaboration mit dem Regime zeugen nicht zuletzt zahlreiche Anfragen von Schriftstellern und Künstlern nach finanziellen Zuwendungen beim Ministerium für Populärkultur. ${ }^{14}$

Die korporatistische Organisation des kulturellen Bereiches wurde auch auf die Bildenden Künste ausgedehnt. 1927 wurde das entsprechende Syndikat gegründet, das sich in 18 regional organisierte Gewerkschaften gliederte. ${ }^{15}$ Die Mitgliedschaft war Voraussetzung für die Teilnahme von Künstlern an Ausstellungen und im großen Stil vom Regime lancierten Wettbewerben um öffentliche Aufträge, mittels derer das faschistische Regime versuchte, die künstlerische Produktion zu lenken. ${ }^{16}$ Während die Mitgliedschaft in den Künstlersyndikaten im faschistischen Italien mit dem Imperativ, der ebenfalls berufsständisch gegliederten Reichskulturkammer im nationalsozialistischen Deutschland beizutreten, vergleichbar ist, war sie im ersteren Fall jedoch nie obligatorisch. $^{17}$

Insgesamt diente die Kulturpolitik den Faschisten als wichtiges Herrschaftsund Integrationsmittel, durch das sie sich versprachen, kulturelle Legitimität zu erlangen und sich des rüpelhaften und von Gewalt geprägten Images der frühen Jahre der faschistischen Herrschaft zu entledigen. ${ }^{18}$ Analog zur proklamierten Neuheit des Regimes forderte Mussolini eine neue, vermeintlich originär faschis-

12 Zimmermann, Medien, S. 69.

13 Ebd., S. 73; Marla Stone, The State as Patron: Making Official Culture in Fascist Italy, in: Matthew Affron, Fascist Visions. Art and Ideology in France and Italy, Princeton 1997, S. 205238, hier S. 208 u. 212.

14 Sedita, Gli intellettuali, S. 183 u. 185.

15 Kate Flint, Art and the Fascist Regime in Italy, in: Oxford Art Journal 3 (1980) 2, S. 49-54, hier S. 50; Stone, Patron, S. 211.

16 Ebd., S. 212.

17 Toby Clark, Kunst und Propaganda. Das politische Bild im 20. Jahrhundert, Köln 1997, S. 60f.; Stone, Patron, S. 219.

18 Gabriele Turi, Faschismus und Kultur, in: Jens Petersen (Hrsg.), Faschismus und Gesellschaft in Italien. Staat - Wirtschaft - Kultur, Köln 1998, S. 91-108, hier S. 99; Stone, Patron, S. 213f. 
tische Kunst, die zur wieder beanspruchten Größe Italiens beitragen sollte. ${ }^{19} \mathrm{Im}$ Hinblick auf die künstlerischen Gattungen wurden dabei die Grenzen zwischen Hoch- und der aufkommenden Populärkultur verwischt und verschiedenste Medien und Ausdrucksformen in den Dienst des Regimes gestellt. ${ }^{20}$ Allerdings blieb offen, was genau unter faschistischer Kunst zu verstehen war. Aufgrund des Ausbleibens konkreter ästhetischer Direktiven herrschte in stilistischer Hinsicht weitgehender Pluralismus. ${ }^{21}$ Daraus folgte, dass auch antithetische ästhetische und kulturelle Strömungen wie Modernismus und Antimodernismus, Internationalismus und Nationalismus, Avantgarde und Traditionalismus koexistieren konnten und in fast gleichwertiger Weise vom Regime gefördert wurden. ${ }^{22}$ Hauptkünstlergruppierungen, die bisweilen darum buhlten, die offizielle Staatskunst $\mathrm{zu}$ repräsentieren, und eng mit dem Regime kollaborierten, indem sie beispielsweise auch Personal für offizielle Posten im Kulturbereich stellten, waren Novecento, Strapaese und der Futurismus. ${ }^{23}$ Während erstere in Formensprache und Themenwahl eher traditionalistisch und nationalistisch orientiert waren, verstand sich der Futurismus explizit als Teil der internationalen Avantgarde. ${ }^{24}$ Bereits in seiner Entstehung eng mit dem Futurismus verbandelt, wurde das faschistische Regime mit seiner sichtbaren Patronage modernistischer Kunstrichtungen zu einer der ersten Nationalregierungen weltweit, die AvantgardeBewegungen in Dienst nahm und massiv finanziell förderte. ${ }^{25}$ Das eklektische und breit gefächerte System staatlicher Kunstpatronage im faschistischen Italien stand insbesondere im krassen Gegensatz zum nationalsozialistischen Deutschland, wo moderne Kunst verfemt und mit dem Attribut ,entartet' belegt wurde. ${ }^{26}$ Trotz der im Laufe der 1930er Jahre immer stärkeren Orientierung an der NS-Kulturpolitik, die zur Bevorzugung von reaktionäreren Kunststilen auch in Italien führte, ist es doch bezeichnend, dass das Projekt, die NS-Ausstellung „Entartete Kunst“ nach Italien zu holen, letztendlich am Widerstand der Futuristen scheiterte. ${ }^{27}$

19 Christine Müller, Franco Veremondi, Die symbolische Form der Zeit. Eine Politik der Künste, in: Jan Tabor (Hrsg.), Kunst und Diktatur, Baden 1994, Band 2, S. 612-615, hier S. 613.

20 Stone, Patron, S. 218.

21 Sedita, Gli intelletuali, S. 181.

22 Ebd.

23 Cioli, „Sua“ arte, S. XI.

24 Ebd., S. 322; Ruth Ben-Ghiat, Fascist Modernites: Italy 1922-1945, Berkeley 2001, S. 26; Stone, Patron, S. 223.

25 Stone, Patron, S. 228.

26 Ebd.; Clark, Kunst, S. 63.

27 Anna D’Elia, L'universo futurista: un mappa, dal quadro alla cravatta, Bari 1988, S. 42. 


\section{Der Arbeiter in der faschistischen Bildpropaganda}

Was die Übersetzung des abstrakten Korporativismus in Bildmedien angeht, so lässt sich neben der Zentralität des Themas der Arbeit eine Dominanz von Körpern feststellen. Die korporatistische Theorie basierte auf intellektuellen Strömungen, die von einer organizistischen Metapher der Nation als Körper ausgingen, dessen Einzelteile nur insofern wichtig waren, als sie das Ganze funktionieren ließen. ${ }^{28}$ Dies zeigt sich auf einem Plakat (Abb. 2) auf die Figur des Diktators zugespitzt: In einer Mischung aus Gattungen sieht man eine aus der

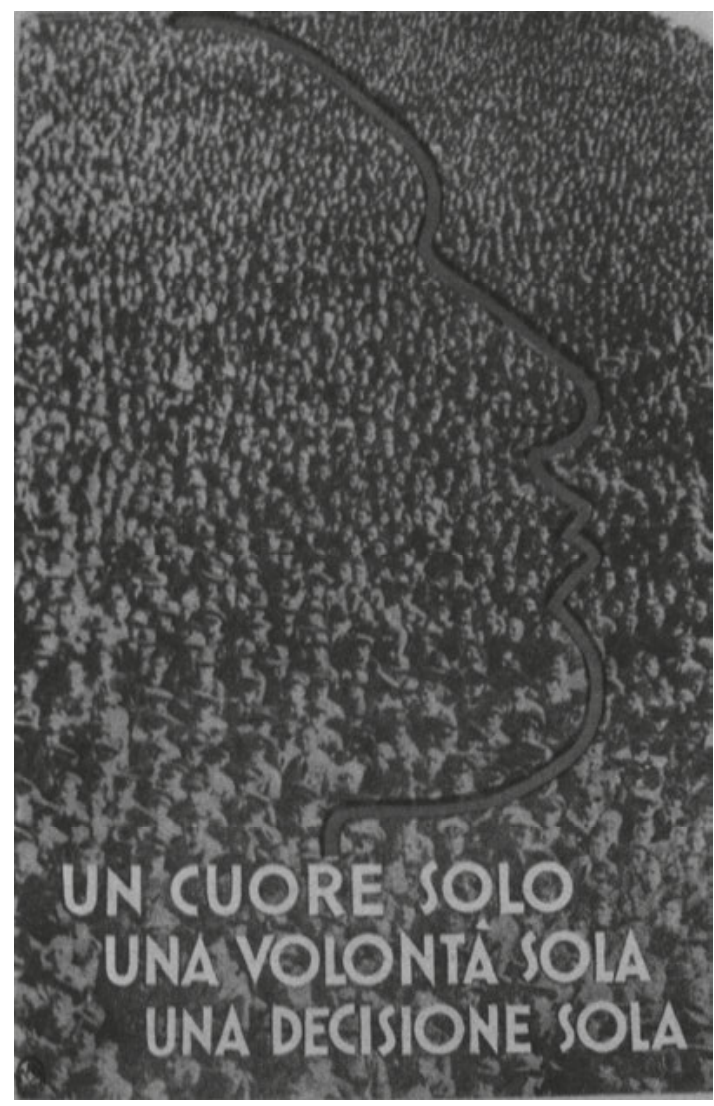

Abb. 2: „Un cuore solo“, Postkarte $105 \times 148 \mathrm{~mm}, 1936$. (C) Raccolta delle Stampe „Achille Bertarelli“, Mailand.

28 Ben-Ghiat, Modernities, S. 17f.; Clark, Kunst, S. 70f. 
Entfernung fotografierte Ansammlung von Menschen, die das gesamte Bild ausfüllt. Darüber ist in Rot Mussolinis Profil gezeichnet. Im übertragenen Sinne konstituiert also die anonyme Masse den Duce. Die Bildunterschrift „Ein einziges Herz, eine einziger Wille, eine einzige Entscheidung“ weist ihn zusätzlich als alleinigen Repräsentanten und Entscheidungsträger der Nation aus. Darüber hinaus inszenierte sich Mussolini als überaus arbeitsam. Mythencharakter haben die Überlieferungen, dass das Licht in seinem Büro im Palazzo Venezia nie erlosch. ${ }^{29}$ Dass Mussolini keinesfalls nur zu intellektueller Arbeit fähig war, schienen massenweise vertriebene Propagandafotografien des 1924 gegründeten Istituto Luce zu belegen. Diese zeigen ihn vorzugsweise oberkörperfrei bei der Getreideernte - ein Anlass, bei dem er sich als vorbildlicher faschistischer Arbeiter gerierte. Sie belegen Mussolinis hemdsärmelige Selbstpräsentation, die ihn deutlich von Hitlers oder Stalins Selbstdarstellungen abhob (Abb. 3).

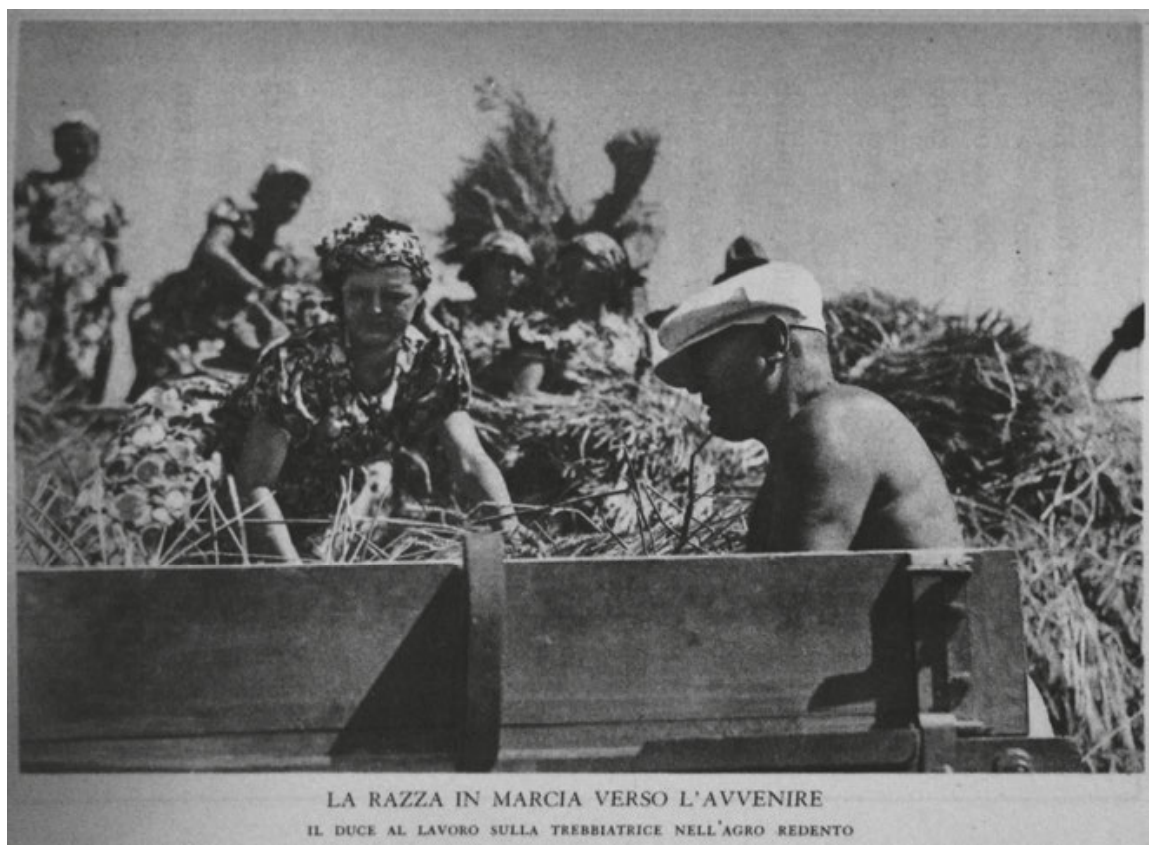

Abb. 3: Mussolini bei der Getreideernte, P.N.F. „Il secondo libro del fascista“, Rom 1939, S. 77. (C) Wolfsoniana - Fondazione regionale per la Cultura e lo Spettacolo, Genua.

29 Simonetta Falasca-Zamponi, Mussolini's Self-Staging, in: Hans-Jörg Czech (Hrsg.), Kunst und Propaganda im Streit der Nationen 1930-1945, Dresden 2007, S. 88-95, hier S. 92. 


\subsection{Stadt und Land}

Wie bereits im Falle von Mussolinis Selbstinszenierung als Landarbeiter angedeutet, lässt sich im Hinblick auf die Frage, welcher Typus Arbeiter vom faschistischen Regime propagiert wurde, die Tendenz feststellen, das Landleben $\mathrm{zu}$ verherrlichen. Im Rahmen der Ruralismus-Ideologie wurde die italienische Bauernschaft idealisiert. ${ }^{30}$ Zum Zeitpunkt des Aufstiegs des Faschismus war Italien ein agrarisch geprägtes Land. Ländliche Großgrundbesitzer und Pächter konstituierten zunächst die traditionelle Stütze des Regimes. ${ }^{31}$ Nachdem die Faschisten an die Macht gelangt waren, trieben sie auch im landwirtschaftli-

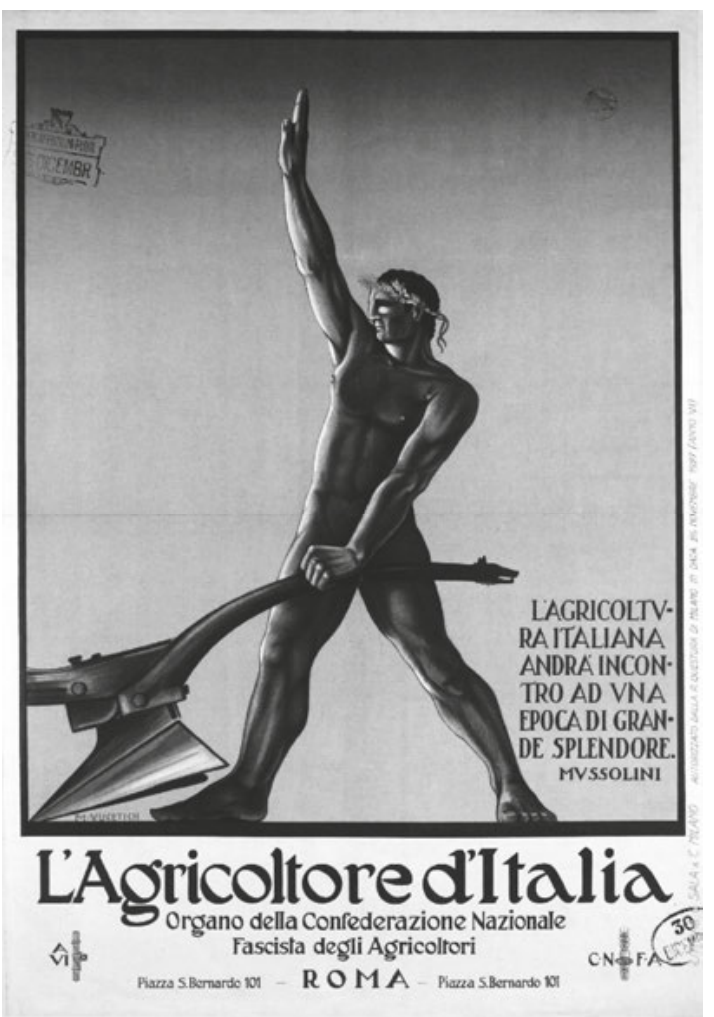

Abb. 4: „L'agricolotore d'Italia“, Zeichner: Mirko Vucetich, Herausgeber: Lit. Rag. C. Sala \& C., Plakat $100 \times 70 \mathrm{~cm}$, Mailand 1927. (C) Raccolta delle Stampe „Achille Bertarelli“, Mailand.

30 Flint, Art, S. 52.

31 Reilly, Emblems, S. 296. 
chen Bereich die Modernisierung voran. ${ }^{32}$ So waren großangelegte Kampagnen der Landgewinnung wie Sumpftrockenlegungen im Agro Pontino Gegenstand der Bildpropaganda. ${ }^{33}$ Insgesamt ist jedoch ein Übergewicht von anachronistischen und zeitlosen Darstellungen von Landarbeitern in der faschistischen Propaganda $\mathrm{zu}$ verzeichnen. ${ }^{34}$ War die korporatistische Theorie durch das mittelalterliche Gildensystem inspiriert ${ }^{35}$, hatten die Landarbeiterfiguren starke ikonographische Anklänge an die römische Antike. ${ }^{36}$ So ist die unbekleidete und sehr muskulös dargestellte Figur auf einer Postkarte (Abb. 4) des nationalen landwirtschaftlichen Verbandes im Stile einer römischen Statue entworfen. Weitere Reminiszenzen an die römische Antike sind der Lorbeerkranz auf dem Kopf sowie die zum römischen bzw. faschistischen Gruß erhobene rechte Hand. ${ }^{37}$ In der anderen Hand hält die Figur einen rudimentären Pflug. Dieses Werkzeug fungiert, abgesehen von der Bildunterschrift, als einziges bildnerisches Mittel, das sie als Landarbeiter ausweist. Angesichts der archaischen Züge der Figur vermittelt lediglich das Zitat Mussolinis eine zukunftsorientierte Perspektive: „Die italienische Landwirtschaft wird in eine Epoche großen Glanzes eintreten“. Im Zusammenhang mit der antikisierenden Darstellung wird somit gleichzeitig die Kontinuität des faschistischen Regimes mit Italiens glorreicher Vergangenheit postuliert. ${ }^{38}$

Ein weiterer Kontext, in dem der Landarbeiter in der Propaganda gepriesen wurde, war die vom Regime verfolgte Autarkiepolitik. Im Rahmen der so genannten Getreideschlacht, die ab 1925 darauf zielte, sich von ausländischen Getreideimporten unabhängig zu machen, wurden Preisgelder ausgeschrieben, um die Agrarier zu mehr Produktion zu animieren. ${ }^{39}$ Auf einem dieser Plakate (Abb. 5) wird ein jugendlicher Landarbeiter mit Getreidebündel im Arm gezeigt. Die beiden Ochsen im Geschirr links neben ihm negieren jedoch die inzwischen vorangeschrittene Mechanisierung der Landwirtschaft.

Die Kehrseite der Verherrlichung des Landlebens war eine negative Sichtweise auf die Stadt als von der Moderne korrumpiertem Raum, in dem Arbeitslosigkeit grassierte und Arbeiter in unmenschlichen Bedingungen lebten. ${ }^{40}$ Diese antiurbanistische Haltung äußerte sich auch in konkreten Maßnahmen, die der

32 Patrizia Dogliani, Il fascismo degli italiani. Una storia sociale, Mailand 2008, S. 125 u. $136 f$.

33 Reilly, Emblems, S. 296.

34 Ebd., S. 295 u. 304.

35 Ebd., S. 304.

36 Bauerkämper, Faschismus, S. 69.

37 Martin Winkler, The Roman Salute: Cinema, History, Ideology, Columbus 2009, S. 2.

38 Reilly, Emblems, S. 304.

39 Nützenadel, Landwirtschaft, S. 109.

40 Falasca-Zamponi, Spectacle, S. 146. 


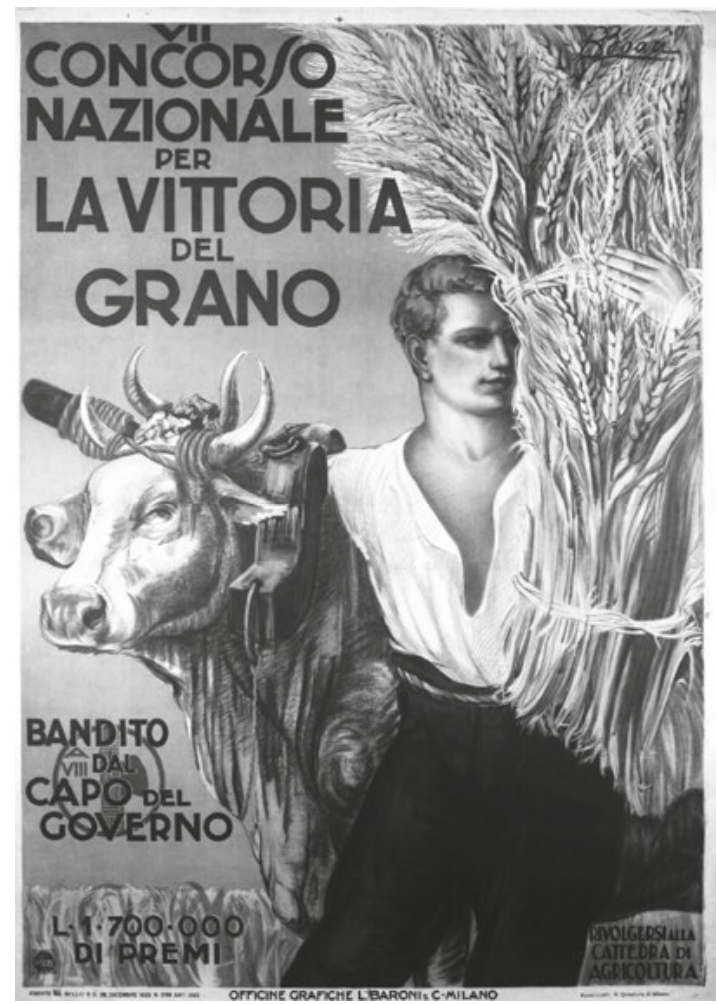

Abb. 5: „La vittoria del grano“, Zeichner: Bruno Boari, Hrsg. Officine Grafiche L. Boari \& C., Plakat $140 \times 100 \mathrm{~cm}$, Mailand ohne Datum. (c) Raccolta delle Stampe „Achille Bertarelli“, Mailand.

Landflucht entgegenwirken sollten. ${ }^{41}$ An dieser Stelle kollidierten die Positionen der offiziellen Propaganda insbesondere mit dem Futurismus, stellte die Idealisierung der Metropolen doch immerhin ein zentrales Element innerhalb des futuristischen Diskurses dar. ${ }^{42}$ Allerdings hatte sich das Verhältnis zwischen Faschisten und Futuristen nach anfänglich enger Kooperation abgekühlt, und bei der Vergabe öffentlicher Aufträge wurden letztere immer weniger berücksichtigt. ${ }^{43}$ Stattdessen standen intellektuelle Gruppierungen wie Strapaese, die die Rückkehr zum Landleben forderten, der ruralistischen Ausrichtung der faschistischen Kulturpolitik in den 1930er-Jahren näher. ${ }^{44}$

Dementsprechend tauchen städtische Arbeiter wesentlich seltener in der faschistischen Bildpropaganda auf. In den wenigen Fällen, in denen Beschäftigte

41 Reilly, Emblems, S. 297.

42 Fochessati, Futurismus, S. 66.

43 Ebd., S. 73.

44 Ben-Ghiat, Modernities, S. 26. 


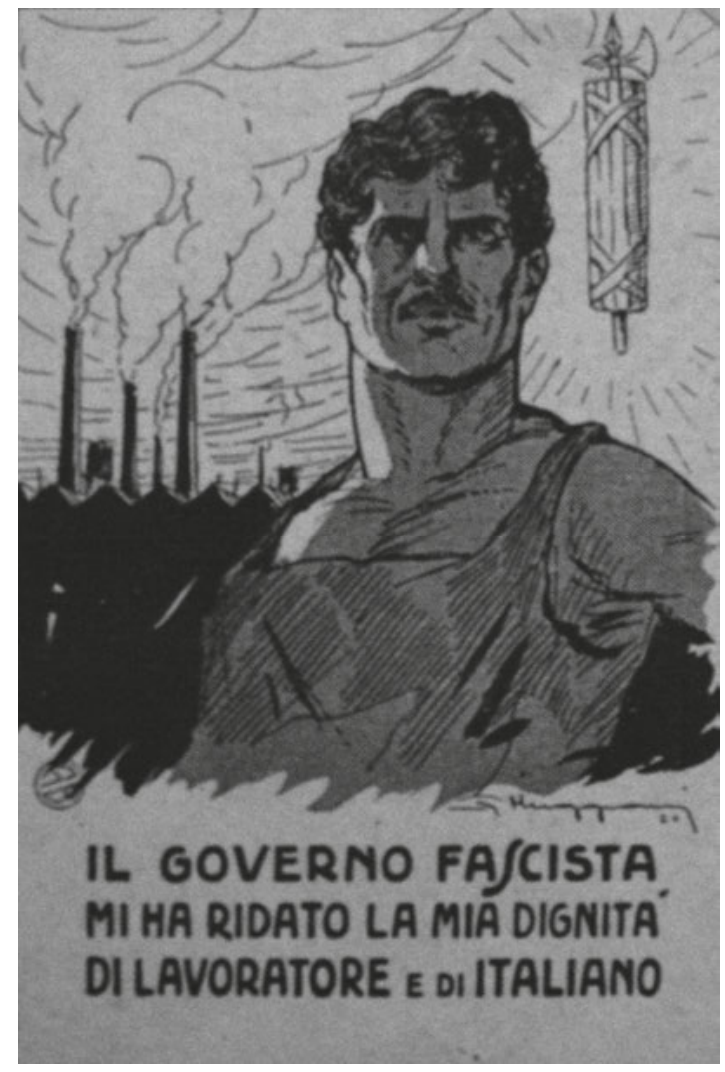

Abb. 6: Industriearbeiter, „Il governo fascista mi ha ridato...“, Zeichner: Giorgio Muggiani, Postkarte 105 × 148 mm , 1924 . (C) Raccolta delle Stampe „Achille Bertarelli“, Mailand.

der Industrie thematisiert werden - ausgewiesen durch ihre Kleidung oder rauchende Fabrikschlote im Hintergrund - wird mittels der Bildunterschrift auf ihre soziale Besserstellung durch die Reformen des faschistischen Regimes, im Bild durch das namensgebende Liktorenbündel (lat. fasces) repräsentiert, abgehoben (Abb. 6). ${ }^{45}$ Trotz der anti-urbanistischen Stoßrichtung des Großteils der propagandistischen Publikationen gab es keine Negativdarstellungen industrieller Arbeit im Faschismus. Sehr wohl wurden jedoch in der Rückschau die Lebensumstände industrieller Arbeiter in vorfaschistischer Zeit angeprangert, oftmals im Modus einer Vorher-Nachher-Darstellung (Abb.7): Während die Vorzeit durch Krisen, Streiks und Unterbezahlung geprägt war, hatte das faschistische Regime für einen gerechten Lohn, Sozialversicherungen und Arbeitsschutz gesorgt.

45 Reilly, Emblems, S. 301. 


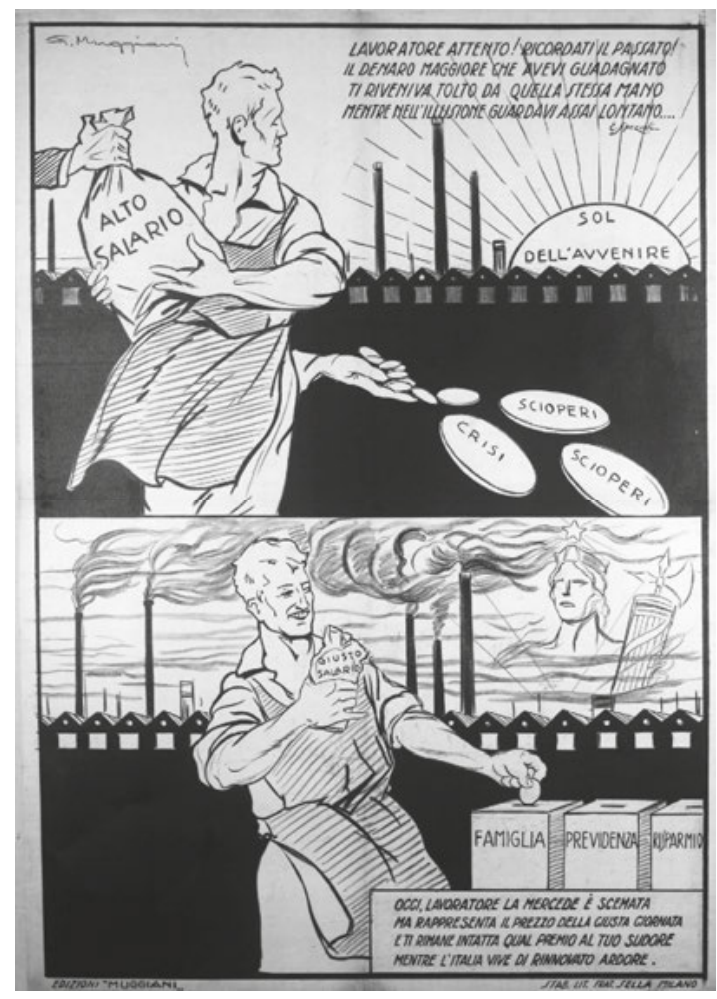

Abb. 7: Industriearbeiter vorher nachher, „Lavoratore attento!“ Zeichner: Giorgio Muggiani , Hrsg. Stab. Lit. F.lli Sella, Mailand, Edizioni Muggiani, Plakat $140 \times 100 \mathrm{~cm}, 1922-38$. (C) Raccolta delle Stampe „Achille Bertarelli“, Mailand.

\subsection{Gender}

Weitgehend übereinstimmend ist die visuelle Propaganda des faschistischen Italiens und des nationalsozialistischen Deutschlands im Hinblick auf die durch sie transportierten Geschlechterrollen. So war die im italienischen stato corporativo zentrale identitätsstiftende Kategorie der Arbeit nicht für beide Geschlechter gleichermaßen gültig. ${ }^{46}$ Frauen wurden hauptsächlich auf ihre Mutterrolle verwiesen und als für die Reproduktion der Nation zuständig befunden. ${ }^{47}$ Wie auch in NS-Deutschland wurden gemäß der pronatalistischen Ausrichtung der faschistischen Familienpolitik kinderreiche Familien gefördert. ${ }^{48}$ Lohnarbeit war allenfalls für junge unverheiratete Frauen denk-

46 Victoria de Grazia, How fascism ruled women, Italy, 1922-1945, Berkeley 1992, S. 168.

47 Perry R. Willson, The clockwork factory. Women and work in Fascist Italy, Oxford 1993, S. 2.

48 Reilly, Emblems, S. 306f. 


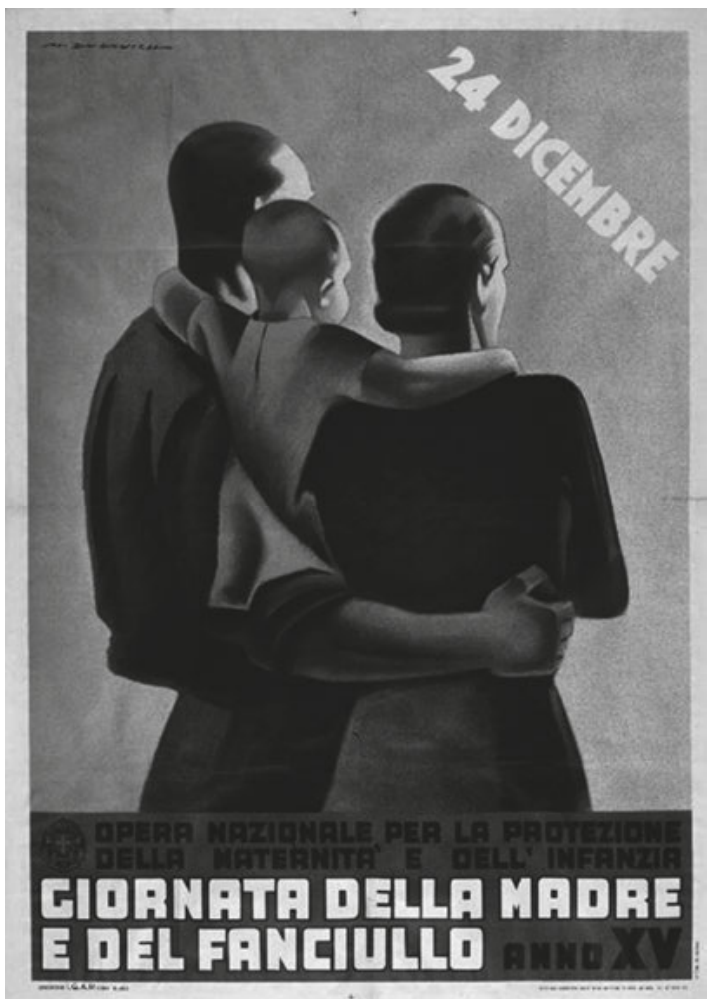

Abb. 8: „Giornata della madre e del fanciullo“, Zeichner: Marcello Dudovich, Technik: Lithographie, Hrsg. Grafiche I. G. A. P., Plakat $140 \times 100 \mathrm{~cm}$, RomMailand ohne Datum. (C) Raccolta delle Stampe „Achille Bertarelli“, Mailand.

bar. ${ }^{49}$ Entsprechend der vorgenommenen Differenzierung zwischen männlicher und weiblicher Arbeit als qualitativ unterschiedlich, waren für Frauen vor allem Tätigkeiten vorgesehen, in denen ihre vermeintlich mütterlichen und weiblichen Fähigkeiten zum Tragen kämen wie soziale und pädagogische Berufe. ${ }^{50} \mathrm{Da}$ Arbeit außer Haus als mit der Mutterrolle konfligierend aufgefasst wurde, sollten Frauen spätestens nach der Heirat aus dem Berufsleben ausscheiden. Haushalte mit so genannten „Doppelverdienern“ wurden denunziert. ${ }^{51}$ Auch in den neuen korporatistischen Institutionen waren Frauen nicht vertreten. Stattdessen wurden sie in einem parallelen Netzwerk von Parteiorganisationen erfasst. Diese zielten jedoch kaum auf die Stärkung ihrer Identität als Arbeiterinnen ab, als sie dort vielmehr klassenübergreifend auf die Unterstützung des Regimes

49 De Grazia, Women, S. 168.

50 Ebd., S. 180 u. $196 f$.

51 Ebd., S. 175. 


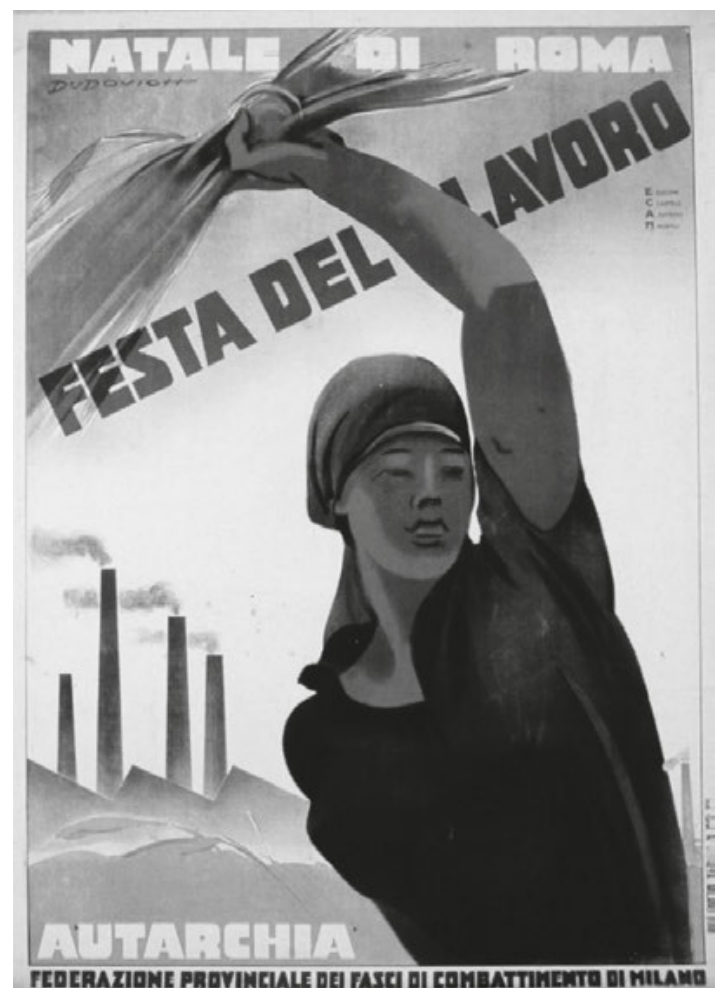

Abb. 9: „Natale di Roma. Festa del lavoro“, Zeichner: Marcello Dudovich, Plakat $140 \times 100 \mathrm{~cm}$, Mailand ohne Datum. (๑ Raccolta Salce Soprintendenza al Patrimonio Storico Artistico e Demoetnoantropologico delle Province di Venezia, Belluno, Padova e Treviso.

eingeschworen werden sollten..$^{52}$ Was die Gesetzgebung anging, wurde im Zuge der Verabschiedung von Arbeitsschutzgesetzen zwar erstmals der Mutterschutz reglementiert. Jedoch fanden diese Maßnahmen keine flächendeckende Anwendung und galten beispielsweise nicht für die Landwirtschaft oder die vom Regime so propagierte Heimarbeit. Im Laufe der 1930er-Jahre folgten dann offen misogyne Gesetze, die die Beschäftigung von Frauen auf minimale Quoten herabsetzten..$^{53}$

Dieses reaktionäre Rollenbild wird auch auf einem Plakat (Abb. 8) des Nationalwerks für den Schutz der Mutterschaft und der Kindheit (Opera Nazionale per la protezione della maternità e dell'infanzia) vermittelt. Generell waren in der faschistischen Propaganda Anleihen bei christlicher Ikonographie häufig. ${ }^{54}$ In

52 Ebd., S. 175 u. 177.

53 Willson, Factory, S. 6.

54 Hierzu Emilio Gentiles grundlegendes und seither viel diskutiertes Werk, in dem er die These vom Faschismus als politischer Ersatzreligion aufstellt: Emilio Gentile, Il culto del littorio. La saccralizzazione della politica nell'Italia fascista, Rom/Bari 1993. 


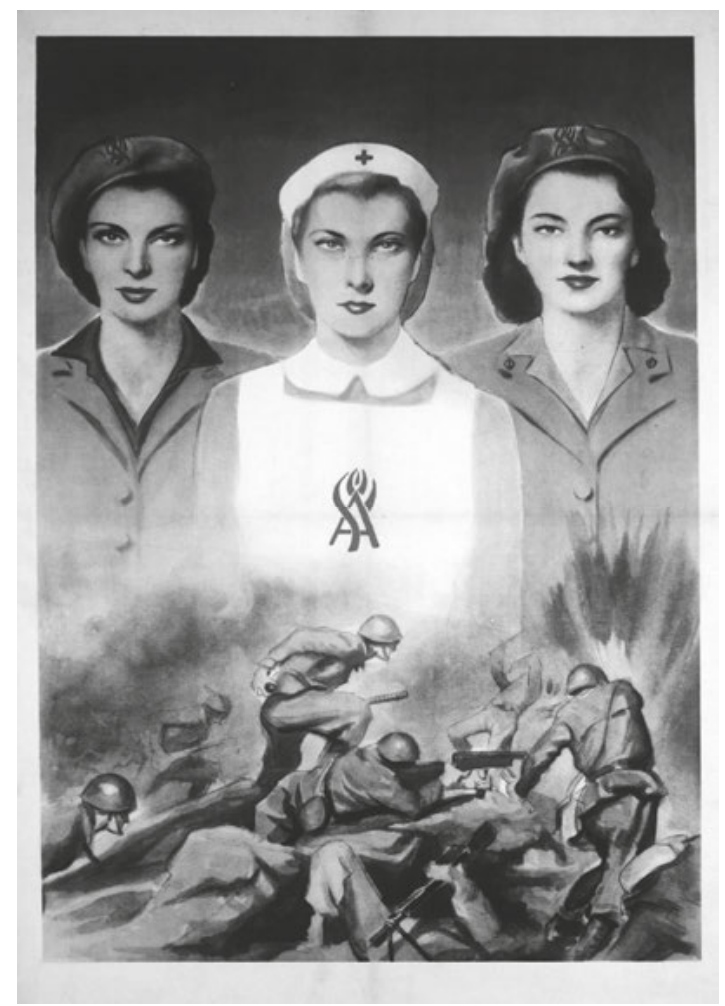

Abb. 10: „Servizi Ausiliari“, Poster $100 \times 70 \mathrm{~cm}, 1943-45$. (C) Raccolta delle Stampe „Achille Bertarelli“, Mailand.

diesem Fall wird die Kernfamilie als geheiligte Domäne dargestellt. Der sakrale Charakter wird durch das Datum des angekündigten Tages der Mutter und des Kindes unterstützt: Es handelt sich um den 24. Dezember. Die Isolation der Familie vor dem simplen, fast monochromen Hintergrund unterstreicht den Eindruck des Geschütztseins vor den Widrigkeiten der modernen urbanen Welt. ${ }^{55}$ In Rückansicht und vom Betrachter abgewandt, blicken sie in eine verheißungsvolle Zukunft, repräsentiert durch eine Lichtquelle am rechten Bildrand.

Außer als Mutter wird die Frau in der faschistischen Bildpropaganda bisweilen als agrarische Arbeiterin dargestellt (Abb.9). Auf dem Plakat der Mailänder Fasci anlässlich des Tags der Arbeit, der vom faschistischen Regime auf den 21. April, den Tag der mythischen Gründung Roms, verlegt wurde, ${ }^{56}$ wird

55 Reilly, Emblems, S. 307.

56 Alexander Nützenadel, Staats- und Parteifeiern im faschistischen Italien, in: Sabine Behrenbeck/Alexander Nützenadel (Hrsg.), Inszenierungen des Nationalstaats. Politische Feiern in Italien und Deutschland seit 1860/71, Köln 2000, S. 127-148, hier S. 134. 


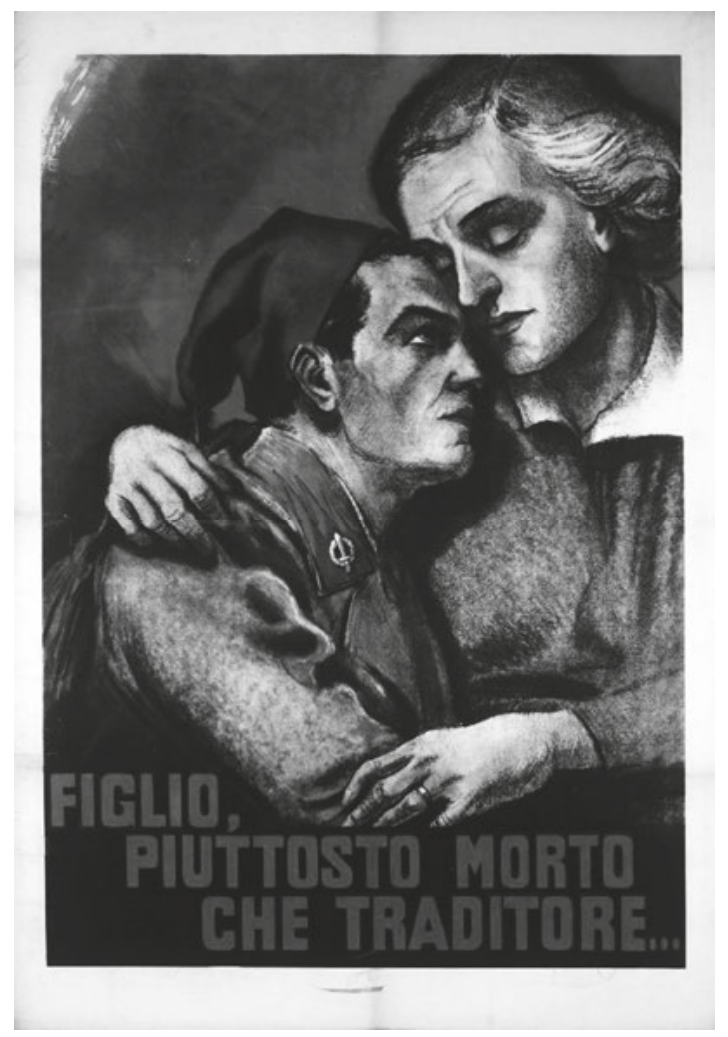

Abb. 11: „Figlio, piuttosto che traditore“, Poster $100 \times 70 \mathrm{~cm}$, Lithographie, 1943-45. (C) Raccolta delle Stampe „Achille Bertarelli“, Mailand.

eine bäuerliche junge Frau im Brustbild gezeigt, die ein Bündel Weizen mit dem linken Arm in die Höhe streckt. Im Hintergrund sind stilisiert ein Weizenfeld und eine industrielle Anlage mit rauchenden Fabrikschloten zu sehen. Zwar ist das Plakat undatiert, die Unterschrift „Autarchia“ verweist jedoch auf die zweite Hälfte der 1930er-Jahre, als nach Verhängung der Sanktionen durch den Völkerbund nach dem Äthiopienkrieg komplette Autarkie angestrebt wurde. ${ }^{57}$

Mit Beginn des Zweiten Weltkriegs und Italiens Kriegseintritt 1940 änderte sich die Arbeitsmarktpolitik: Frauen wurden nun massenhaft in die Lohnarbeit gedrängt, um die weggefallenen männlichen Arbeiter zu ersetzen. ${ }^{58}$ Auf den Propagandaplakaten aus der Zeit der Italienischen Sozialrepublik (Repubblica Sociale Italiana, 1943-45) wird dieser Aspekt jedoch größtenteils übergangen, und Frauen werden weiterhin hauptsächlich bei für sie als geeignet befundenen

57 Nützenadel, Landwirtschaft, S. 345.

58 De Grazia, Women, S. 177. 
Tätigkeiten gezeigt (Abb. 10). Hier treten sie hauptsächlich als Krankenschwestern im Rahmen der Hilfsdienste (Servizi Ausiliari) auf. Eine weitere Variante, in der Frauen zu Kriegszeiten in der visuellen Propaganda auftauchen, ist erneut die Mutterrolle, in diesem Fall jedoch als Mütter von Soldaten, die ihre Söhne mit den Worten in den Krieg verabschieden, sie sollten lieber sterben als zu Verrätern werden (Abb. 11).

\subsection{Nationale Identität und Rassismus}

Die Bildpropaganda ist auch eine überaus aussagekräftige Quelle, wenn es um die Konstruktion einer nationalen Identität geht, nicht zuletzt über Strategien der Abgrenzung. Der italienische Rassismus unter Mussolini richtete seine xenophoben Attacken dabei zunächst gegen Slawen und Afrikaner, während ein biologisch begründeter Antisemitismus anfangs keine große Rolle spielte. ${ }^{59}$ So gab es beispielsweise anlässlich des Äthiopienkrieges 1935 massive rassistische Propagandakampagnen, ${ }^{60}$ die die „Zivilisierungsmission“ der Italiener als ultimative Rechtfertigung für das spätkoloniale Unternehmen anführten. ${ }^{61}$ Das Motiv, der lokalen Bevölkerung das Arbeiten beibringen zu müssen, ist ein wiederkehrendes in der faschistischen Propaganda. Auf der eingangs beschriebenen Postkarte (Abb. 1) ist im Hintergrund die koloniale Situation in Nordafrika angedeutet. Mit in die Hüften gestemmten Armen steht ein schmächtiger Dunkelhäutiger in vermeintlich ortstypischer Kleidung tatenlos da und beobachtet den beispielhaften italienischen Arbeiter. Auch wenn in der Bildunterschrift nicht explizit auf den nordafrikanischen Kontext abgehoben wird, unterstreicht auch sie den vorbildlichen Charakter italienischer Arbeit, der im Rahmen der „Zivilisierungsmission“ von zentraler Bedeutung war.

Spätestens im Zuge der Annäherung an das nationalsozialistische Deutschland bekannte sich auch das faschistische Italien mit der Verabschiedung der Rassegesetze 1938 offen zum Rassen-Antisemitismus. So richtet sich das Titelblatt (Abb.12) der ab 1938 erscheinenden Zeitschrift La difesa della razza ${ }^{62}$ nicht nur gegen Afrikaner, sondern auch gegen Juden. Versetzt und überlappend im Profil gezeigt, erscheinen die Köpfe einer antiken Statue, eines stereotypisierten

59 Schieder, Diktaturen, S. 323.

60 Marco Giuman, Ciro Parodo, Nigra subucula induti. Immagini, classicità e questione della razza nella propaganda dell'Italia fascista, Padua 2011; Manfredi Martelli, La propaganda razziale in Italia 1938-1943, Rimini 2005.

61 Manfredi Martelli, La propaganda razziale in Italia 1938-1943, Rimini 2005, S. 219.

62 „Die Verteidigung der Rasse“ (eigene Übersetzung). 


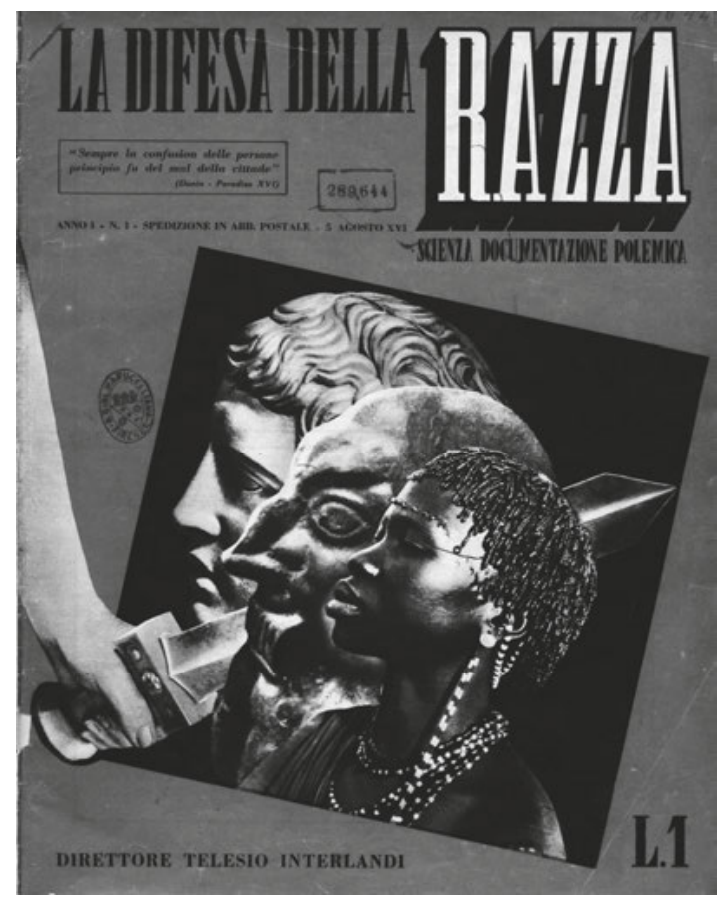

Abb. 12: Cover „La difesa della razza“, Jahrgang I, N. 1, 5. August 1937. () Biblioteca Marucelliana, Florenz.

Juden sowie einer Afrikanerin. Der durch das Haupt der klassischen Skulptur kodifizierte Italiener wird mit einem Schwert, was vom Bildrand hereinreicht, aus der Reihe der anderen separiert. Hierbei wird die Konstruktion der italianità mittels ikonographischer Anleihen bei der römischen Antike erneut deutlich. Dass die Trennung mit einer Waffe vollzogen wird, steht für die Bereitschaft des faschistischen Regimes, die eigene Rasse gewaltsam zu verteidigen, wie auch der Titel der Zeitschrift nahelegt. In technischer Hinsicht verweisen der Stilmix und die Kollage aus Fotographie und Graphik auf die vom Faschismus im Gegensatz zum Nationalsozialismus durchaus häufig genutzte modernistische Ästhetik.

Bezüglich der Arbeitsthematik in Verbindung mit antisemitischen Motiven erschien 1942 in derselben Zeitschrift ein illustrierter Artikel über zu Arbeit verpflichtete Juden (Abb. 13). Während Überschrift und Text auf die pseudowissenschaftliche Klassifizierung der Schädelformen von Juden abheben, bedient die graphische und fotographische Illustration im Modus einer Vorher-NachherDarstellung das Klischee vom ehemals parasitären Juden, der nun zur Arbeit gezwungen werde. Im Hinblick auf Einflüsse und Adoptionen aus Deutschland ist bemerkenswert, dass es ab 1939 unter der Überschrift „Juden lernen arbeiten!“ eine ganz ähnliche Kampagne in deutschen Bildmedien gegeben hat- 


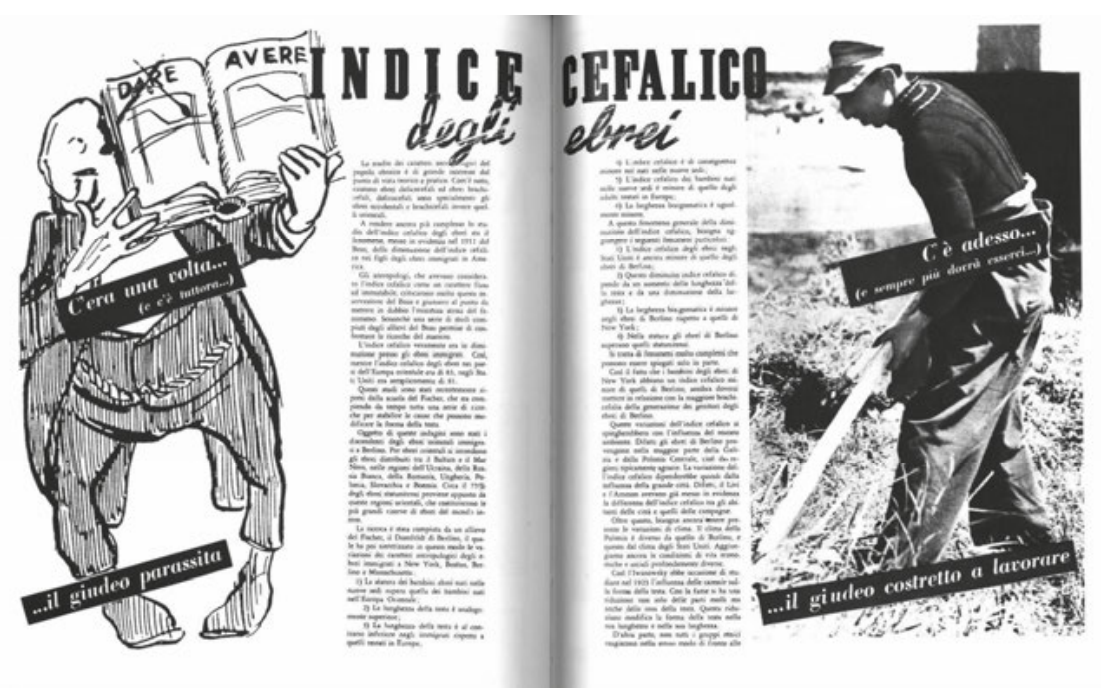

Abb. 13: „....il giudeo costretto a lavorare“, in: „La difesa della razza“, Jahrgang V, N. 16, 20. Juni 1941. (๖ Biblioteca Marucelliana, Florenz.

te. ${ }^{63}$ Während in diesem Fall wie in vielen weiteren die Konvergenzen der Argumentationslinie und Darstellungsweise in der Bildpropaganda beider Regime offensichtlich sind, steht die Aufarbeitung der genauen Modalitäten eines Transfers in personeller oder konzeptueller Hinsicht noch aus.

\subsection{Autarkie und die Militarisierung des Arbeitsbegriffs}

Die Verhängung von Völkerbundssanktionen über Italien in Folge des Äthiopienkrieges Mitte der 1930er-Jahre führte zur Steigerung autarkistischer Bestrebungen, die auch in die Bildpropaganda Eingang fanden. ${ }^{64}$ Eine Postkarte (Abb. 14) anlässlich des Tages des italienischen Produktes zeigt in futuristischer, abstrakter Formensprache eine stilisierte Figur in der Diagonalen, die mit einem Hammer auf einen Amboss einschlägt. Dies lässt einen nach rechts oben sprühenden Funkenstrahl entstehen, der in den italienischen Nationalfarben gehalten ist. Die in futuristischer Ästhetik ausgeführte Komposition ist voller

63 Hierzu der Beitrag von Harriet Scharnberg in diesem Band.

64 Nützenadel, Landwirtschaft, S. 345. 


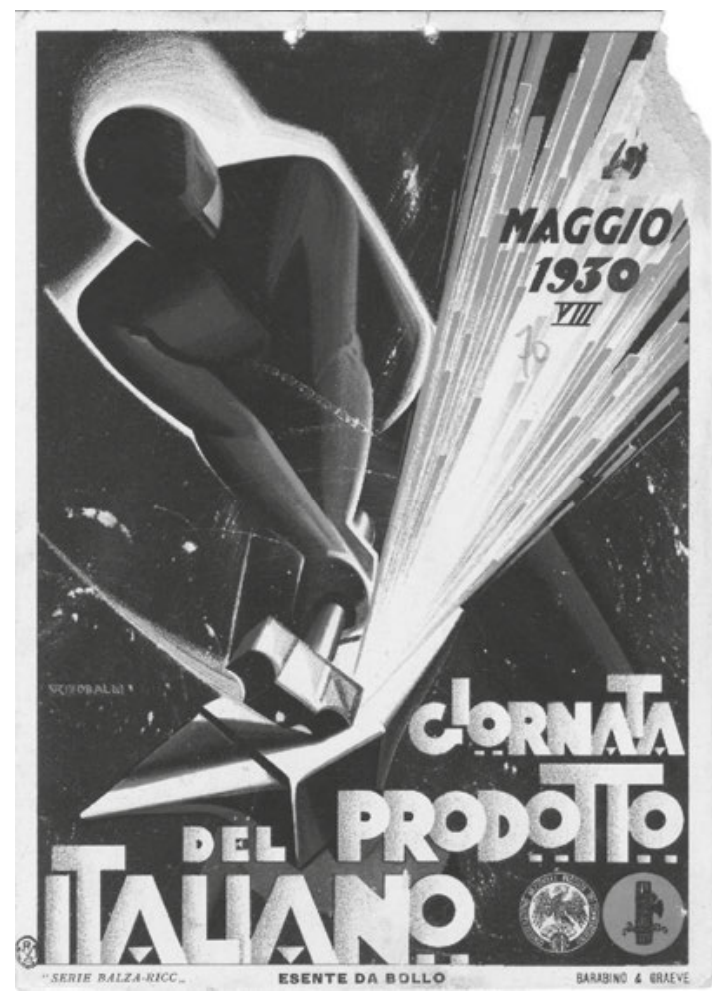

Abb. 14: „Giornata del prodotto italiano“, Zeichner: Giuseppe Riccobaldi Del Bava, Lithographie, Hrsg. Barabino \& Graeve, $23,7 \times 16,9 \mathrm{~cm}$, Genua 1930. (C) Raccolta delle Stampe „Achille Bertarelli“, Mailand.

Dynamik, was als Verweis auf die Leistungsfähigkeit der italienischen Wirtschaft gedeutet werden kann.

Eine andere Postkarte (Abb. 15) ruft zum ausschließlichen Erwerb italienischer Produkte auf. Die Überschrift „Sanktionen“ wird bezeichnenderweise vom Rauch, der aus den unzähligen Fabrikschloten dringt, die perspektivisch bis in den Hintergrund schier endlos fortgeführt werden, geschwärzt, so dass sie kaum noch erkennbar ist. Damit soll der Eindruck erweckt werden, dass die Fortschrittlichkeit der italienischen Industrie die Auswirkungen der Sanktionen zunichtemache. Während generell die Landarbeit als das Idealbild faschistischer Arbeitspropaganda erscheint, ist die Industrie hauptsächlich im Kontext von Sanktionen und Autarkiebestrebungen Thema, verweist aber auf kein Ideal. Meist liegt der Fokus auf der Modernität der Industrieanlagen selbst, ohne dass dort notwendigerweise Industriearbeiter als moderne Heroen auftauchen. 


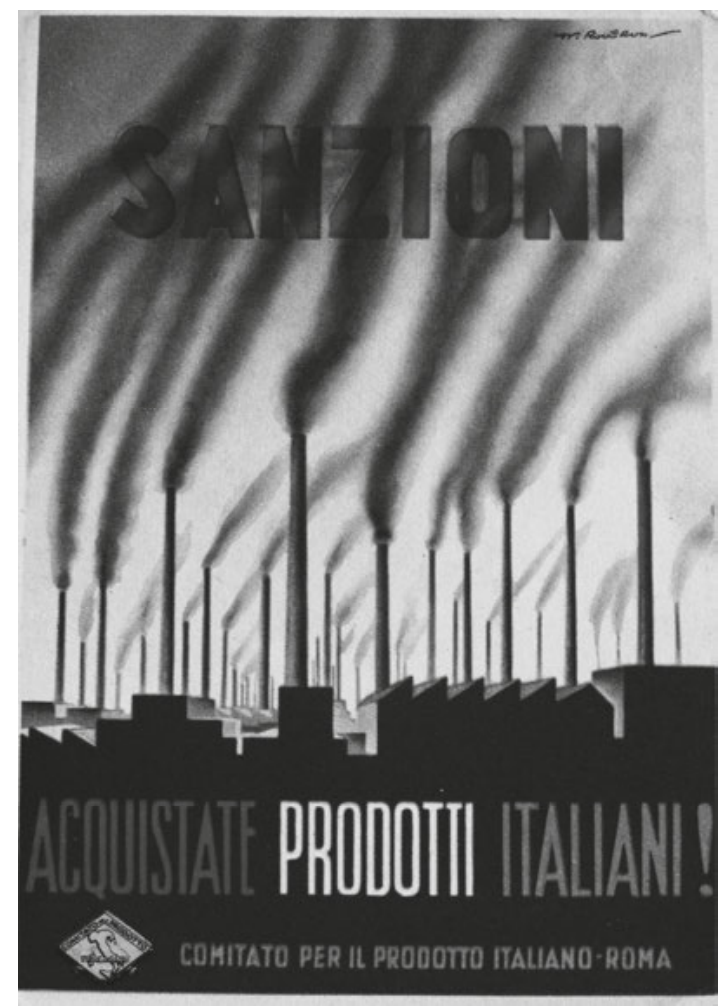

Abb. 15: „Sanzioni“, Postkarte $105 \times 148 \mathrm{~mm}$, Hrsg. Comitato per il prodotto italiano, Rom ohne Datum. (c) Wolfsoniana Fondazione regionale per la Cultura e lo Spettacolo, Genua.

Wie im nationalsozialistischen Deutschland ${ }^{65}$ ist mit Herannahen des Zweiten Weltkriegs auch in Italien eine zunehmende Militarisierung des Arbeitsbegriffs festzustellen. In der faschistischen Propaganda wurde nach dem Kriegseintritt Italiens jeder, der nicht an der Front kämpfte, dazu aufgerufen, durch seinen Arbeitseinsatz zu Hause einen Beitrag zu leisten. Und dies galt für verschiedene Berufsgruppen gleichermaßen. Auf einem Plakat (Abb. 16) mit dem Titel „Arbeiten und kämpfen für das Vaterland, für den Sieg“ sind ein Soldat und ein Schmied im Profil bzw. Halbprofil in Ganzkörperansicht dargestellt, wie sie sich die Hand reichen. Außer durch ihre Kleidung sind sie durch die Attribute, Gewehr respektive Hammer und Amboss, charakterisiert. Während der Handschlag den gemeinsamen Aufwand repräsentiert, wird der Schulterschluss zwischen beiden durch die Überkreuzung von Schrift und Bild - der Soldat

65 Hierzu der Beitrag von Inge Marszolek in diesem Band. 


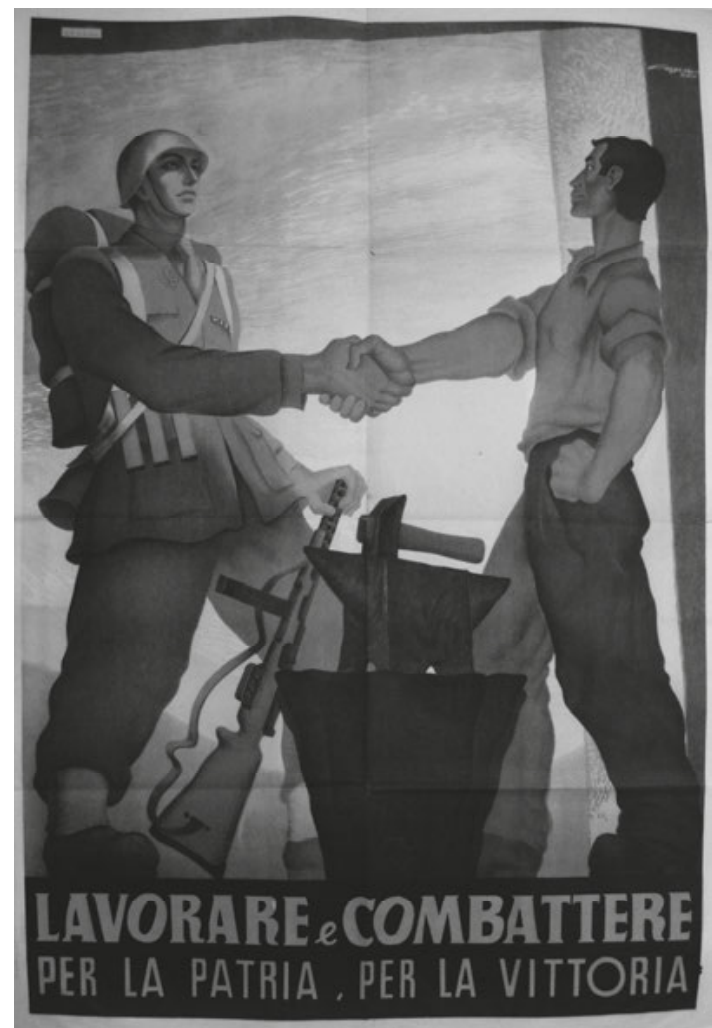

Abb. 16: „Lavorare e combattere“, Plakat $70 \times 100 \mathrm{~cm}$, ohne Datum. (c) Archivio di Stato ForlìCesena.

steht über dem Schriftzug ,arbeiten`, der Arbeiter ist mit ,kämpfen` unterschrieben - noch verstärkt.

Jedoch wurden nicht nur Handarbeiter, sondern auch Angehörige freier Berufe in der visuellen Propaganda dazu angehalten, den Krieg durch ihre Arbeit zu unterstützen. In diesem Fall (Abb. 17) sitzt eine männliche Figur im Brustbild im Vordergrund; der weiße Kittel sowie Bleistift und Zirkel weisen ihn als Architekten oder Naturwissenschaftler aus. Das Kriegsgeschehen ist in den Hintergrund verlegt, wo Granaten werfende Soldaten auszumachen sind. Durch die Bildunterschrift „In Zusammenarbeit - Arbeitet für Italien!“ werden beide Bildebenen verknüpft und auf die geforderte gemeinsame Kriegsanstrengung abgehoben. 


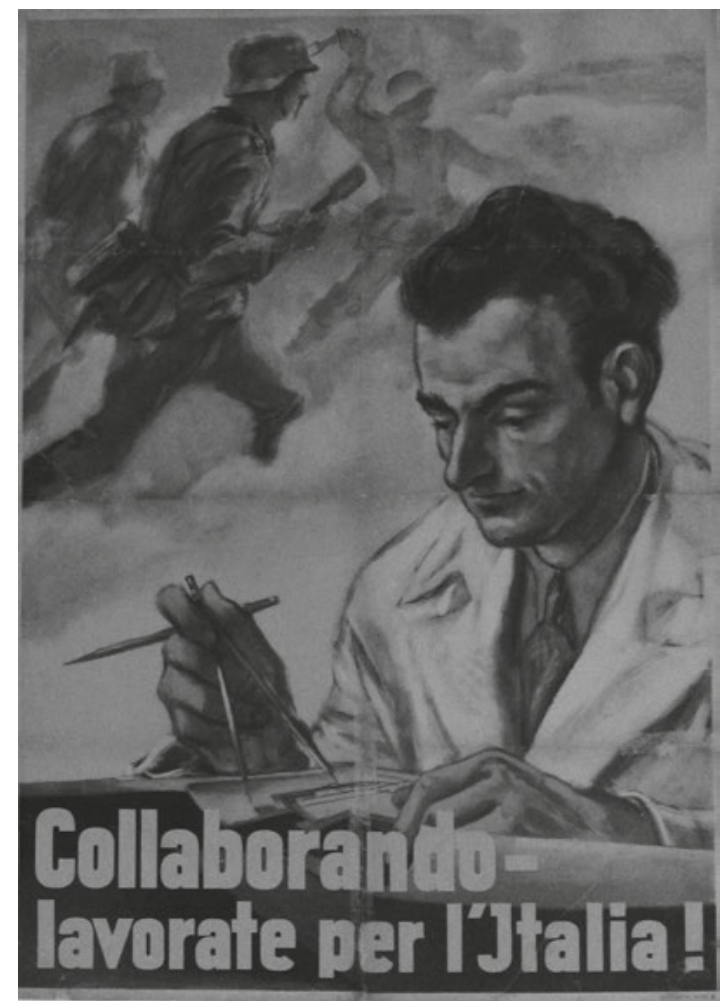

Abb. 17: „Collaborando...“, Plakat $70 \times 100 \mathrm{~cm}$, ohne Datum. (C) Archivio di Stato Forlì-Cesena.

\section{Fazit}

Mit der Verabschiedung der Carta del Lavoro 1927 wurde Arbeit zur sozialen Pflicht und zur Voraussetzung für die Zugehörigkeit zum Volkskörper erklärt. Dabei wurden in anachronistischer Weise wie auch im nationalsozialistischen Deutschland vorrangig Bauern und Landarbeiter zu nationalen Helden erklärt, während die für die Kriegsanstrengungen viel wesentlichere Industrie in der Bildpropaganda seltener auftauchte. Zwar wurde bisweilen auf die Modernisierung der Industrie als Leistung des Regimes abgehoben, sie verwies aber nicht auf eine faschistische oder nationalsozialistische Utopie. Mehrheitlich blieb auch im italienischen Faschismus wie im Großteil der konservativen Strömungen des 19. Jahrhunderts die Industrie eher eine Bedrohung durch Vermassung als ein Idealbild. Hiervon wichen in Italien am entschiedensten die Futuristen ab.

Bezüglich Gender lassen sich ebenso Übereinstimmungen zwischen faschistischer und nationalsozialistischer Propaganda konstatieren. So waren für 
die Geschlechter grundlegend verschiedene Beschäftigungen vorgesehen: Der Mann wurde als für den Erwerb des Lebensunterhaltes zuständig befunden; Haus und Heim sollten hingegen den Hauptarbeitsplatz von Frauen darstellen.

Während in der Frühphase des Faschismus der Antisemitismus wenig ausgeprägt war und Juden auch vielfach unter den Mitgliedern der Faschistischen Partei zu finden waren ${ }^{66}$, flammten rassistische Ressentiments gegenüber Afrikanern spätestens im Umfeld des Äthiopienkrieges auf und wurden zum Gegenstand der visuellen Propaganda. Nach zunehmender Annäherung an NS-Deutschland Ende der 1930er-Jahre verstärkte sich der Antisemitismus auch in Italien, was die Rezeption und Reproduktion antisemitischer Bildproduktion mit einschloss. Das Motiv der Arbeit tauchte dann nicht mehr in seiner inklusiven Variante als Versprechen der Zugehörigkeit zur Nation auf, sondern als Strafe. Angesichts des nahenden Krieges wurden die Aufrufe zu mehr Produktion zunehmend mit dem Kriegsaufwand verknüpft. Die zuvor in der Propaganda zentrale ländliche Arbeiterfigur wurde nun sukzessive durch die des Soldaten ersetzt.

66 Dogliani, Il fascismo, S. 312. 